Hruzevskyi O. A., Minukhin V. V., Vastyanov R. S. The relationship between the immune system activity and the bacterial vaginosis development. Journal of Education, Health and Sport. 2020;10(3):272-286. eISSN 2391-8306. DOI http://dx.doi.org/10.12775/JEHS.2020.10.03.029

https://apcz.umk.pl/czasopisma/index.php/JEHS/article/view/JEHS.2020.10.03.029

https://zenodo.org/record/4432700

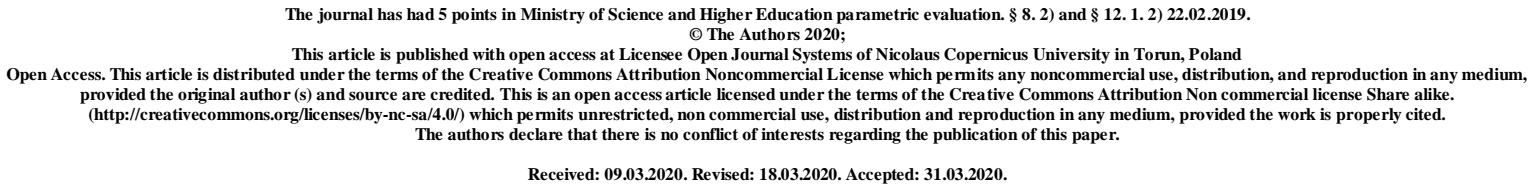

UDC 619:616:41:636.12:611.4

\title{
THE RELATIONSHIP BETWEEN THE IMMUNE SYSTEM ACTIVITY AND THE BACTERIAL VAGINOSIS DEVELOPMENT
}

\author{
O. A. Hruzevskyi ${ }^{1}$, V. V. Minukhin ${ }^{2}$, R. S. Vastyanov ${ }^{1}$
}

\section{Odessa National Medical University, Odessa, Ukraine}

\section{${ }^{2}$ I.I. Mechnikov Institute of Microbiology and Immunology of National Academy of Medical Sciences of Ukraine, Kharkov, Ukraine}

\begin{abstract}
The main cause of bacterial vaginosis (BV) is immunodeficiency which is both systemic and local in nature and increases in parallel to a dysbiosis grade deepening. It is of great importance to link the indicators of $\mathrm{BV}$-associated microbiota with individual indicators of systemic immune responses. The aim of the study is to establish a relationship between the immune system state and the development of various grades bacterial dysbiosis and BV. The study selected 298 women, who were divided into groups according to the index of conditionally pathogenic microflora (ICPM): in normocenosis ICPM was lower than $-3 \mathrm{lg}$ $\mathrm{GE} /$ sample $(\mathrm{n}=53)$; in grade I dysbiosis it was from -3 to $-1 \mathrm{lg} \mathrm{GE} / \mathrm{sample}(\mathrm{n}=128)$; and in grade II dysbiosis (BV) it was more than -1 lg GE/sample $(\mathrm{n}=117)$. Molecular-genetic studies of the scraping of epithelium from the posterolateral vaginal paries were performed using the method of polymerase chain reaction (DNA technology, RF). Optional and obligate anaerobes, myco- and ureplasms and yeast fungi were quantified. Content in the blood of fractions of T-and B-lymphocytes, immunoglobulins, cytokines, complement, lymphocyte phagocytic activity (LPA), 21 indicators in total) were determined using standard
\end{abstract}


immunological methods. Interrelation between the microbial biocenosis with the considered indicators was studied using the regression analysis (Statistica 10; StatSoft, Inc., USA).

In normocenosis, normobiota indicator (NBI) was determined by activation of complement $\left(\mathrm{C}_{4}\right)$, PA - as well by activation of complement $\left(\mathrm{C}_{3}\right)$ and by content of sIgA in blood; ObA and YF - by $\gamma$-INF level, and YF - also by IL8, IL10 and SIgA levels; ICPM effective value was determined by the number of $\mathrm{CD} 22^{+}$lymphocytes. In grade I dysbiosis, NBI depended on the number of CD22 ${ }^{+}$lymphocytes, IL6, IgM, IgG, LPI, CIC, IL10, which indicated the implementation of various mechanisms and involvement of almost all of the immune system levers to compensate for dysbiosis at the beginning of its formation. In grade I dysbiosis, ObA amount was also affected by IL6 and IL10, and MU amount - by IL1 $\beta$ and IgG. In grade II dysbiosis, no factors affected NBI, which indicated that the dysbiotic processes went beyond the control of the immune system. Content of IL1 $\beta$ in blood reflected a shift of the ICPM: when its level exceeded $24.6 \mathrm{pg} / \mathrm{ml}$, grade II dysbiosis was present; at IL1 $\beta$ level from $9.6 \mathrm{pg} / \mathrm{ml}$ to $24.6 \mathrm{pg} / \mathrm{ml}$ - it was grade I dysbiosis, and at IL1 $\beta$ level less than $9.6 \mathrm{pg} / \mathrm{ml}$ - it was normocenosis. Factors, which anaerobic dysbiosis was the trigger for, were activation of the humoral immunity (IgG secretion) and IL10 increase.

General analysis of the interrelation between the immune system indicators with the number of pathogenic microbiota revealed the development of systemic combined immunodeficiency and "slipping" of the most pathogenic microorganisms out of the control of the immune system.

Keywords: immune system; bacterial vaginosis; pathogenic microbiota; system immune response; immunodeficiency

Introduction. Bacterial vaginosis (BV) is a clinical manifestation of vaginal microbiota dysbiosis, manifested by an increase of the number of obligate and optional anaerobic ( $\mathrm{ObA}$ and $\mathrm{FacA}$ ) conditionally pathogenic microorganisms in the vaginal content with a decrease or absence of normobiota - Lactobacillus $s$. [1,2]. The frequency of BV has been increasing recently, ranging from $26 \%$ to $40-45 \%[1,3]$. BV has great medical importance, since the increase of streptococcus and staphylococci and enterobacteria in the microbiota, as well as candidiasis, cause inflammatory diseases of the pelvic organs in nonpregnant women, and in pregnancy - premature births and infections of the mother and newborn child $[4,5]$. In addition, $\mathrm{BV}$ has been shown to cause an increased sensitivity to HIV- [6] and papillomavirus infection associated with the development of cervical cancer [7, 
8]. In the United States, $29 \%$ of women are affected by BV, and in sub-Saharan Africa, where HIV is widespread, it is $52 \%$ [8].

It is believed that the main cause of BV is local immunodeficiency, which leads to a decrease in colonization resistance of vaginal secretions, disorder of the secretion of antimicrobial agents and impaired provision of local immune protection $[9,10]$. In addition to local immunodeficiency, under the condition of BV it acquires systemic nature [11].

The first link of protection are the antigen-presenting vaginal cells (macrophages and dendritic cells), which are activated by molecular antigens of pathogens and, through the release of proinflammatory cytokines, trigger the cellular and humoral immunity components [12]. In addition, the antibodies produced by local B-lymphocytes play an important role. IgG and IgA antibodies with inflammatory transudate enter the mucous membrane from the general circulation $[11,13]$. In $\mathrm{BV}$, both systemic and local inflammatory responses are reduced [14], which corresponds to an increase in BV-associated pathogens, especially Gardnerella vaginalis and Mycoplasma hominis [15].

Thus, it is relevant and necessary to find out the effect of the immune system indicator on the vaginal microbial biocenosis in the development of various grade bacterial dysbiosis and BV.

The aim of the study - to establish a relationship between the immune system state and the development of various grades bacterial dysbiosis and BV.

\section{Material and methods}

This study uses examination data of 298 women aged from 16 to 64 who saw gynecologist for a preventive examination or with complaints of genital discomfort. Criterion for exclusion was the presence of definitely pathogenic microorganisms (Trichomonas vaginalis, Neisseria gonorrhoeae, Chlamydia trachomatis and Herpes Simplex Virus 1,2) in the material taken. Presence in the smear of more than 15-20 leukocytes, which indicated of an inflammatory reaction, was also the reason for exclusion from the number of patients.

During the examination, scraping of epithelium from the posterolateral vaginal paries was made using a urogenital probe. Molecular-genetic studies were performed using polymerase chain reaction (PCR) method. DNA was extracted using a kit of reagents "ProbaGS" ("DNK-Technologiia" LLC, RF). Amplification of tubes with the reaction mixture was performed in the amplifier "DTLite" ("DNK-Technologiia" LLC, RF) using the amplification programs recommended by the manufacturer of the reagent kit. Investigation of vaginal biocenosis status was performed using "Femoflora 16" test system, intended to perform realtime PCR. Biota was quantified by the following indicators [16]: total bacterial mass (TBM), 
normobiota (Lactobacillus spp.; NB), obligate anaerobes (ObA; Atopobium vaginalis, Eubacterium spp., Gardnerella vaginalis, Prevotella bivia, Porphyromonas spp., Lachnobacterium spp., Clostridium spp., Megasphaera spp., Veilonella spp., Dialister spp., Mobilunory spp., Mobilunory spp., Mobiluncus spp. Peptostreptococ spp., Sneathia spp., Leptotrihia spp., Fusobacterium spp.), facultative anaerobes (FacA; Enterobacteriaceae spp., Staphylococcus spp., Streptococcus spp.), mycoplasmas (MU; Ureaplasma ureali ticum + parvum, Mycoplasma hominis + genitalium) and yeast-like fungi (YF; Candida spp.).

Criteria for the distribution of patients into groups was an index of conditionally pathogenic microflora (ICPM) which was calculated as the difference between the sum of all conditionally pathogenic microorganisms and the number of lactobacilli in lg GE/sample. In normocenosis ICPM was lower than $-3 \lg$ GE/sample ( $1^{\text {st }}$ group, $\left.\mathrm{n}=53\right)$; in grade I dysbiosis it was from -3 to -1 lg GE/sample ( $2^{\text {nd }}$ group, $\mathrm{n}=128$ ); and in grade II dysbiosis (BV) it was more than $-1 \lg$ GE/sample ( $3^{\text {rd }}$ group, $\left.\mathrm{n}=117\right)$ [17].

According to the PCR results, the following total and derived indicators were calculated: $\mathrm{NBI}=\lg \mathrm{TBM}-\operatorname{lgLB} ; \Sigma \mathrm{ObA}=\lg (\Sigma 10 \mathrm{ObA}) ; \Sigma \mathrm{FacA}=\lg (\Sigma 10 \mathrm{FacA}) ; \Sigma \mathrm{MP}=\lg (\Sigma 10 \mathrm{MP}) ; \Sigma \mathrm{FY}$ $=\lg (\Sigma 10 \mathrm{FY}) ; \mathrm{ICPM}=\lg ((\Sigma 10 \mathrm{ObA}+\Sigma 10 \mathrm{FacA}+\Sigma 10 \mathrm{MP}+10 \mathrm{FY})-10 \mathrm{LB})$, where: NBI normobiota indicator; TBM - total bacterial mass; LB - Lactobacilli; ObA - obligate aerobes; FacA - facultative anaerobes; MP - mycoplasma; YF - yeast-like fungi; ICPM - index of conditionally pathogenic microflora.

In all patients in the fasted state there was collected 3-4 $\mathrm{ml}$ of blood from a cubital vein. The blood tubes were centrifuged to obtain serum. Using standard immunological methods $[19,20]$, contents of immunoglobulins $\mathrm{A}(\operatorname{IgA}), \mathrm{M}(\operatorname{IgM})$ and $\mathrm{G}(\operatorname{IgG})$ in the vaginal fluid (test systems NVL "Granum"; Ukraine), content of immunoglobulin G2 (IgG2) and secretory IgA (sIgA) ("Hema" LLC; RF), content of transforming growth factor $1 \beta$ (TGF-1 $\beta$ ) (DRG; USA), circulating immune complexes (CIC) by the method of selective precipitation in a solution of polyethylene glycol, content of interleukins $1 \beta$ (IL1 $\beta$ ), 2 (IL2), 4 (IL4), 6 (IL6), 8 (IL8), 10 (IL10), tumor necrosis factor $\alpha$ (TNF $\alpha$ ) and $\gamma$-interferon ( $\gamma$-INF) ("Vektorbest" LLC; RF), content of components of complement C3 and C4 ("PLIVA-Lachema Diagnostica s.r.o"; Czech Republic) were defined. Leukocyte phagocytic activity (LPA) was defined using yeast cell suspension (Granum NPL, Ukraine); LPA was calculated as the average number of particles absorbed by one active neutrophil per 100 cells; LPA index was calculated as the percentage of phagocytes from the counted neutrophils. Quantitative determination of $\mathrm{CD} 3+, \mathrm{CD} 4+, \mathrm{CD} 16+$, and $\mathrm{CD} 22+$ cells was performed using erythrocyte diagnostic agents manufactured by Granum NPP (Ukraine). 
To identify the interrelation between microbial biocenosis indicators and colonization resistance factor, regression analysis, method for detecting the effect of one or more independent (factor) variables on a dependent variable (Statistica 10, StatSoft Inc., USA), has been used.

\section{Results}

Our previous studies $[17,18,21,22]$ showed that in dysbiosis on the background of general lymphocytosis there was a gradual, related to the increasing severity of dysbiosis, decrease in the content of CD3- and CD4-lymphocytes in blood, which was expressed to a maximum extent in $\mathrm{BV}$. This allowed us to establish the progression of $\mathrm{T}$-cell immunodeficiency in the development of dysbiosis.

Dependence of the degree of progression of dysbiosis and activation of NK-cells $\left(\mathrm{CD} 16^{+}\right)$and B-lymphocytes $\left(\mathrm{CD} 22^{+}\right)$, which reached the maximum degree in BV, was revealed. With increasing severity of dysbiosis, = formation of phagocytosis deficiency was showed, which was also more inherent for BV. Immunodeficiency was manifested by a decrease of $\operatorname{IgA}$ and $\operatorname{sIg} \mathrm{A}$ amid increasing $\operatorname{IgM}$. Content of $\operatorname{IgG}$ and $\mathrm{IgG}_{2}$ tended to increase. Content of all cytokines in blood increased as dysbiosis deepened, and it reached a maximum in BV. $\gamma$-INF reaction was two-phase: activation of synthesis occurred in dysbiosis, whereas inhibition of its synthesis occurred in severe dysbiosis. IL4 and IL10 levels decreased according to the grade dysbiosis, which was expressed to maximum extent in BV. In severe dysbiosis and BV, TGF- $1 \beta$ levels were equally elevated. The complement system was activated during grade I dysbiosis, with a parallel increase in $\mathrm{C}_{3}$ and $\mathrm{C}_{4}$ indicating that complement was activated by a classical pathway (IgM increase and CIC accumulation). In grade II dysbiosis, levels of $\mathrm{C}_{3}$ and $\mathrm{C}_{4}$ were reduced, which indicated a decrease in activation of the complement system by a classical pathway and a possible switch to an alternative pathway (accumulation of bacterial lipopolysaccharides in blood).

In this work, we focus on identifying the interrelations between the immunological parameters studied and the PCR data with the estimation of the number of certain biocenosis indicators. Table 1 shows the dependence of microbial biocenosis indices on immunological parameters in normocenosis, grade I and II dysbiosis. Regression analysis was performed for all indicators, but only statistically significant ones $(\mathrm{p}<0.05)$ are presented in the table 1 .

In normocenosis, NBI was determined by complement activation (component C4); FacA - also by activation of complement (component C3) and sIgA level; ObA and YF - by $\gamma$-INF level, and YF - also by IL8, IL10 and SIgA levels; effective ICPM value was determined by the number of B-lymphocytes (CD22+). Indicators of complement, $\gamma$-INF and 
IL8 had positive $\beta$-coefficients, that is, these indicators increased with the shift of biocenosis towards dysbiosis. sIgA and IL10 values had negative $\beta$-coefficients, that is, these parameters decreased as the biocenosis shifted toward the prevalence of normobiota. Therefore, complement, $\gamma$-INF and IL8 responded positively to the growth of conditionally pathogenic microflora, and SIgA and IL10 - negatively.

For the integrative index - ICPM - there was only one influential factor: number of CD22-lymphocytes in blood. This indicator had a negative sign, that is, under normocenosis, with decreasing of CD22-lymphocytes, ICPM increased (which reflected a possible shift towards the pathogenic microflora).

In grade I dysbiosis, NBI depended on a number of factors (Table 1). The grade of dysbiosis increased (positive $\beta$-coefficient) when CD22-lymphocytes, IL6, IgM and IgG increased and decreased (negative $\beta$-coefficient) when IFAL, CIC, IL10 increased. This indicated the implementation of various mechanisms and involvement of almost all of the immune system levers to compensate for dysbiosis at the beginning of its formation. Therefore, the factor, which dysbiosis was a triggering factor for, was the activation of the humoral immunity component. Activity of phagocytosis, formation of CEC and IL10 directly reduced the grade of dysbiosis.

The results obtained can be explained from the point of view of [23], where it is showed that IL-1 $\beta$, IL-8 and IL-6 in physiological concentrations stimulate the growth of normal microflora (Lactobacillus spp.) and inhibit the growth and formation of S. aureus biofilm and collibacillus. Extreme cytokines concentrations (which are typical for BV), in contrast, inhibit Lactobacillus spp. and stimulate the growth of pathogenic microorganisms.

In grade I dysbiosis, amount of ObA was affected by IL6 and IL10, and the amount of MU - by IL1 $\beta$ and IgG. Number of FacA, YF and ICPM in grade I dysbiosis was not affected by any factors.

Thus, the growth of pathogenic BV-associated microflora is related to the activation of the cytokine-producing function of dendritic cells: genital antigen presenting cells recognize gram-negative bacteria through Toll-4 receptors with activation of the NF-kB signaling pathway, expression of cytokines and lymphocytes recruiting [24, 25].

In grade II dysbiosis, no factors influenced NBI, which could indicate that the dysbiotic processes had gone beyond the control of the immune system and reflected the development of systemic immunodeficiency. Number of FacA depended on several factors, including the fact, that dysbiosis became more severe (positive $\beta$-coefficient) when the 
number of CD22-lymphocytes, IL10 and IgG increased, and decreased (negative $\beta$ coefficient) when the content of lymphocytes in blood increased.

Table 1

Dependence of the estimated indicators of microbial biocenosis on immunological indicators

\begin{tabular}{|c|c|c|c|c|c|c|c|c|c|}
\hline \multirow{2}{*}{$\begin{array}{c}\text { Biocenosis } \\
\text { indicator }\end{array}$} & \multicolumn{3}{|c|}{ Normocenosis } & \multicolumn{2}{c|}{ Grade I dysbiosis } & \multicolumn{2}{c|}{ Grade II dysbiosis } \\
\cline { 2 - 10 } & ImI & $\beta$ & $p$ & ImI & $\beta$ & $p$ & ImI & $\beta$ & $p$ \\
\hline NBI & C4 & 0,398 & 0,036 & CD22 & 0,175 & 0,006 & - & - & - \\
& & & & IFAL & $-0,133$ & 0,033 & & & \\
& & & & CIC & $-0,138$ & 0,027 & & & \\
& & & & IL6 & 0,196 & 0,019 & & & \\
& & & & IL10 & $-0,218$ & 0,001 & & & \\
& & & & IgM & 0,171 & 0,011 & & & \\
\hline FacA & C3 & 0,430 & 0,002 & - & - & - & Lc & $-0,261$ & 0,021 \\
& sIgA & $-0,353$ & 0,036 & & & & CD22 & 0,289 & 0,028 \\
& & & & & & & IL10 & 0,519 & 0,018 \\
& & & & & & & IgG & 0,318 & 0,002 \\
\hline ObA & $\gamma$-INF & 0,563 & 0,002 & IL6 & $-0,355$ & 0,023 & IL2 & 0,203 & 0,047 \\
& & & & IL10 & 0,251 & 0,040 & IgM & $-0,326$ & 0,001 \\
\hline MU & - & - & - & IL1 $\beta$ & 0,325 & 0,009 & IgA & 0,338 & 0,006 \\
& & & & IgG & $-0,280$ & 0,009 & & & \\
\hline YF & $\gamma$-INF & 0,535 & 0,001 & - & - & - & $\gamma$-INF & $-0,331$ & 0,041 \\
& IL8 & 0,381 & 0,043 & & & & & & \\
& IL10 & $-0,329$ & 0,035 & & & & & & \\
\hline ICPM & SIgA & $-0,423$ & 0,005 & & & & & & \\
& CD22 & $-0,378$ & 0,032 & - & - & - & IL1 $\beta$ & 0,345 & 0,020 \\
\hline
\end{tabular}

Notes: ImI - immunological index; Lc -lymphocytic count in blood; $\beta$ - regression coefficient; $p$ - the statistical significance of the investigated index (Kruscall-Wallis statistical criteria).

Therefore, the factors, which the dysbiosis was a trigger for, were activation of the humoral immunity component, namely, IgG secretion, and increased IL10 level. Lymphocytosis reduced the number of FacA. Number of ObA increased when IL2 level increased, and decreased when IgM content increased. Increased number of MU provoked the activation of IgA secretion. Number of YF decreased under the influence of $\gamma$-IFN.

The main integral indicator - ICPM - in grade II dysbiosis directly corresponded to the increase of IL1 $\beta$ level, that is, this indicator could demonstrably reflect the severity of dysbiosis under the condition of BV. This provision was verified by performing classification analysis using a classification tree (QUEST method; StatSoft, Inc., USA). Group identifiers 
were used as the dependent variable: " $\mathrm{N}$ " is normocenosis $(\mathrm{n}=53)$, " $\mathrm{D}_{1}$ " is grade I dysbiosis $(\mathrm{n}=128)$ and " $\mathrm{D}_{2}$ " is grade II dysbiosis $(\mathrm{n}=117)$. A continuous series of IL1 $\beta$ level values were used as the dependent value. The resulting tree structure has two branches and five nodes, three of which are terminal (Fig).

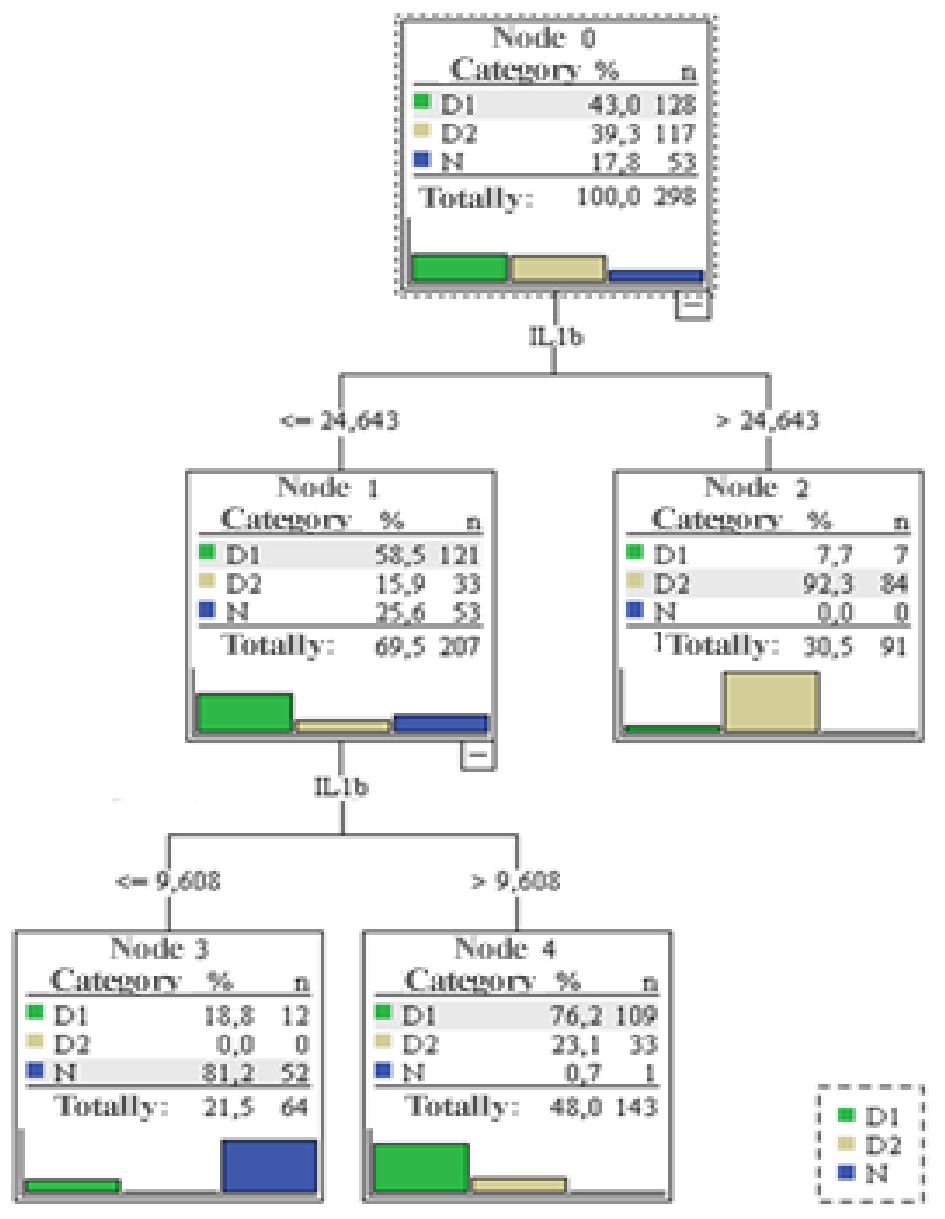

Fig. Structure of the classification tree by group characteristic depending on the value of content of IL1 $\beta$ in blood; $\mathrm{N}$ - normocenosis, $\mathrm{D}_{1}$ - grade I dysbiosis, $\mathrm{D}_{2}$ - grade II dysbiosis

At the top of the tree there is a root node (marked as 0 ). The root node then branches into two nodes, one of which is terminal. It means, that all patients with IL1 $\beta$ content in blood exceeding $24.6 \mathrm{pg} / \mathrm{ml}$ shall be referred to node 2 and, accordingly, can be with $92.3 \%$ of probability classified as having grade II dysbiosis. The rest of the cases with IL1 $\beta$ content in blood not more than $24.6 \mathrm{pg} / \mathrm{ml}$ were referred to node 1 . The latter further branched into two more terminal nodes: patients with IL1 $\beta$ content in blood exceeding $9.6 \mathrm{pg} / \mathrm{ml}$ can be predominantly $(76,2 \%)$ classified as having grade I dysbiosis (node 4), and patient with IL1 $\beta$ content in blood not exceeding $9,6 \mathrm{pg} / \mathrm{ml}$ in $81,2 \%$ of cases can be referred to normocenosis group (node 3). 
The aim of any classification is to obtain the most accurate forecast, which gives the lowest percentage of incorrect distributions. Table 2 summarizes the results of assessment of possibilities to classify the patients by group characteristics, depending on the content of IL1 $\beta$ in blood.

Table 2

\section{Results of classification by group characteristics depending on the content of IL1 $\beta$ in}

\section{blood}

\begin{tabular}{|c|c|c|c|c|}
\hline Forecast results & \multicolumn{3}{|c|}{ Factual information } & \multirow{2}{*}{$\begin{array}{c}\text { Share of correct } \\
\text { forecasts }\end{array}$} \\
\cline { 2 - 4 } & $\mathrm{D}_{2}, \mathrm{n}=117$ & $\mathrm{D}_{1}, \mathrm{n}=128$ & $\mathrm{~N}, \mathrm{n}=53$ & 0,718 \\
\hline $\mathrm{D}_{2}$ & 84 & 7 & 0 & 0,851 \\
\hline $\mathrm{D}_{1}$ & 33 & 109 & 1 & 0,981 \\
\hline $\mathrm{N}$ & 0 & 12 & 52 & \\
\hline
\end{tabular}

Notes: $\mathrm{N}$ - normocenosis, $\mathrm{D}_{1}$ - grade I dysbiosis, $\mathrm{D}_{2}$ - grade II dysbiosis

Thus, increase of IL1 $\beta$ content in blood is clearly related to the integral indicator of dysbiosis - ICPM - and actually corresponds to the patient's assignment to certain group, and, therefore, has a diagnostic value: if the content of IL1 $\beta$ in blood is more than $24.6 \mathrm{pg} / \mathrm{ml}$, then it is grade II dysbiosis, if the content is from 9.6 to $24.6 \mathrm{pg} / \mathrm{ml}$ - grade I dysbiosis, and if less than $9.6 \mathrm{pg} / \mathrm{ml}$ - normocenosis.

According to $[10,14]$, an increase in vaginal secretion of IL-1 $\beta$ is characteristic for BV on the background of immunodeficiency. This correlates with an increase in the number of BVassociated bacteria - Gardnerella vaginalis and Mycoplasma hominis [15]. The results also indicate the possibility of using the content of IL-1 $\beta$ in blood as an immunological marker of BV diagnostics, which is consistent with the data of [26, 27]. Studies [28] showed that IL-1 $\beta$, among other cytokines, is a biomarker of BV detection.

We have previously shown $[17,22]$ that grade I dysbiosis was characterized by a decrease in the incidence of enterobacteria, candida and Ureaplasma urealiticum + parvum and an increased rate of detection of staphylococci, Megasphaera spp. + Veilonella spp. + Dialister spp. and Lachnobacterium spp. + Clostridium spp.; some Sneathia spp. + Leptotrihia spp. + Fusobacterium spp. appeared. Grade II dysbiosis was characterized by the disappearance of streptococci and a decrease in the number of Eubacterium spp. in patients over 45 old with an increased incidence of ObA, especially Mobiluncus spp. + Corynebacterium spp. and Atopobium vaginalis. The main features of BV were the decline of lactobacilli, progression of 
anaerobic dysbiosis, increase of Sneathia spp. + Leptotrihia spp. + Fusobacterium spp., Mycoand ureplasm.

According to the results obtained, dependence of key microbial factors on immune system indicators was analyzed (Table 3). Regression analysis was performed for all indicators, but only statistically significant ones $(\mathrm{p}<0.05)$ are presented in the Table3.

Table 3

\section{Dependence of quantitative indicators of microbial biocenosis on the immune system}

\section{indicators}

\begin{tabular}{|c|c|c|c|c|c|c|c|c|c|}
\hline \multirow{2}{*}{$\begin{array}{l}\text { Biocenosis } \\
\text { indicator }\end{array}$} & \multicolumn{3}{|c|}{ Normocenosis } & \multicolumn{3}{|c|}{ Grade I dysbiosis } & \multicolumn{3}{|c|}{ Grade II dysbiosis } \\
\hline & ImI & $\beta$ & $\mathrm{p}$ & ImI & $\beta$ & $\mathrm{p}$ & ImI & $\beta$ & $\mathrm{p}$ \\
\hline $\begin{array}{c}\text { Lactobacillus } \\
\text { spp. }\end{array}$ & sIgA & $-0,391$ & 0,034 & $\begin{array}{c}\text { IL10 } \\
\text { IgG }\end{array}$ & $\begin{array}{c}0,417 \\
-0,314\end{array}$ & $\begin{array}{l}0,001 \\
0,001\end{array}$ & $\operatorname{IgM}$ & $-0,257$ & 0,010 \\
\hline $\begin{array}{c}\text { Streptococ-cus } \\
\text { spp. }\end{array}$ & - & - & - & $\operatorname{IgA}$ & $-0,243$ & 0,017 & $\begin{array}{l}\text { CD3 } \\
\text { CD8 }\end{array}$ & $\begin{array}{c}-0,308 \\
0,627\end{array}$ & $\begin{array}{l}0,050 \\
0,040\end{array}$ \\
\hline $\begin{array}{c}\text { Atopobium } \\
\text { vaginalis }\end{array}$ & $\begin{array}{c}\text { ILPA } \\
\mathrm{C}_{3} \\
\text { sIgA }\end{array}$ & $\begin{array}{l}0,306 \\
0,491 \\
0,314\end{array}$ & $\begin{array}{l}0,039 \\
0,004 \\
0,039\end{array}$ & $\mathrm{TNF} \alpha$ & $-0,390$ & 0,003 & $\begin{array}{c}\text { LPA } \\
\text { IL1 } \beta \\
\text { IgA }\end{array}$ & $\begin{array}{l}0,376 \\
0,329 \\
0,235\end{array}$ & $\begin{array}{l}0,038 \\
0,042 \\
0,041\end{array}$ \\
\hline $\begin{array}{c}\text { Gardn/ } \\
\text { Prevot/ } \\
\text { Porhphyr }\end{array}$ & $\begin{array}{l}\text { CD22 } \\
\text { LPA } \\
\text { sIgA }\end{array}$ & $\begin{array}{c}-0,354 \\
0,384 \\
-0,346\end{array}$ & $\begin{array}{l}0,034 \\
0,045 \\
0,037\end{array}$ & - & - & - & IgM & $-0,301$ & 0,004 \\
\hline $\begin{array}{c}\text { Mobilun/ } \\
\text { Coryneb spp. }\end{array}$ & - & - & - & - & - & - & - & - & - \\
\hline $\begin{array}{l}\text { Peptostrepto- } \\
\text { coc spp. }\end{array}$ & - & - & - & - & - & - & $\begin{array}{l}\text { IgM } \\
\text { IgG }\end{array}$ & $\begin{array}{l}-0,297 \\
-0,223\end{array}$ & $\begin{array}{l}0,004 \\
0,029\end{array}$ \\
\hline $\begin{array}{l}\text { Sneat/Lept/ } \\
\text { Fusob spp. }\end{array}$ & - & - & - & $\begin{array}{c}\text { CD16 } \\
\text { TGF-1 } \beta \\
\text { IgM } \\
\text { IgA }\end{array}$ & $\begin{array}{c}-0,191 \\
0,236 \\
-0,260 \\
-0,212\end{array}$ & $\begin{array}{l}0,044 \\
0,018 \\
0,047 \\
0,029\end{array}$ & $\begin{array}{c}\text { CD16 } \\
\text { CD22 } \\
\text { LPA } \\
\text { IL1 } \beta \\
\text { IgM } \\
\text { IgA }\end{array}$ & $\begin{array}{c}0,214 \\
-0,241 \\
0,475 \\
0,499 \\
-0,250 \\
0,257\end{array}$ & $\begin{array}{l}0,014 \\
0,040 \\
0,006 \\
0,001 \\
0,008 \\
0,018\end{array}$ \\
\hline $\begin{array}{l}\text { Ureaplasma } \\
\text { urea }+ \text { parv }\end{array}$ & - & - & - & $\begin{array}{c}\text { IL1 } \beta \\
\text { IgG }\end{array}$ & $\begin{array}{c}0,325 \\
-0,281\end{array}$ & $\begin{array}{l}0,008 \\
0,009\end{array}$ & $\operatorname{IgA}$ & 0,332 & 0,007 \\
\hline $\begin{array}{c}\text { Mycoplasma } \\
\text { hom }+ \text { gen }\end{array}$ & - & - & - & IL10 & 0,276 & 0,041 & - & - & - \\
\hline
\end{tabular}

Notes: ImI - immunological index; $\beta$ - regression coefficient, $\mathrm{p}-$ its statistical significance (accepted at $\mathrm{p}$ <0.05); Gardn/Prevot/Porhphyr - Gardnerella vaginalis, Prevotella bivia, Porphyromonas spp.; Mobilun / Coryneb spp - Mobiluncus spp., Corynebacterium spp.; Sneat/Lept/Fusob spp. - Sneathia spp., Leptotrihia spp., Fusobacterium spp.

Analysis of the data obtained showed that the level of lactobacilli in normocenosis inversely correlated with the content of SIgA in blood; in grade I dysbiosis - with IgG, and in 
grade II dysbiosis - with IgM. This reflected the presence of humoral immunity control. In normocenosis, content of streptococci was not related to the immune system, whereas in grade I dysbiosis it inversely depended on the level of $\operatorname{IgA}$, content of which in vaginal secretion decreased [18, 21], and in grade II dysbiosis - on indicators of cellular immunity: inversely - on the number of CD3-lymphocytes and directly - on the number of CD8lymphocytes.

Therefore, lack of humoral and cellular immunity determined the growth of streptococci in vaginal content. In grade I dysbiosis, streptococci level had a positive correlation only with IgA, and in grade II dysbiosis, it had no correlation with the immune system at all.

To control the number of anaerobes being markers for BV - Atopobium vaginalis and Gardnerella vaginalis + Prevotella bivia + Porphyromonas spp. in normocenosis, were significant activation of complement (component $\mathrm{C}_{3}$ ), phagocytosis activity, as well as content of $\mathrm{CD}_{22}$-lymphocyte and sIgA in blood. That is, several immune system components have been involved in preventing the growth of these anaerobes, which has been quite effective. In dysbiosis dysbiosis, these anaerobes apparently "slipped" out of immune control. Yes, in grade I, Atopobium vaginalis correlated only with TNFa level, whereas Gardnerella vaginalis + Prevotella bivia + Porphyromonas spp. had no relationship with the immune system at all.

According to [29], Gardnerella vaginalis is of key importance in the etiology of BV, because it reduces the cytokine-forming function of antigen presenting cells of the mucous membrane of the vagina, which causes an atypically weak immune response. BV-associated bacteria Megasphaera and Prevotella are able to activate dendritic cells of the mucous membrane of the vagina and increase the content of proinflammatory cytokines, and Prevotella causes the development of cellular immune responses through activation of type 1 helpers (Th1) [30]. In addition, Prevotella stimulates epithelial cells to produce IL-8, IL-6 and CCL20, which activates neutrophil recruitment [24].

In grade II dysbiosis, only for LPA (level of which in the vaginal content was decreased [21]), IL1 $\beta$, and IgA had control over Atopobium vaginalis. All the indicators had positive $\beta$ coefficients, which reflected their parallel growth (that is, they did not stop the growth of this pathogenic microflora). As for Gardnerella vaginalis + Prevotella bivia + Porphyromonas spp., only IgM had an inverse correlation with them. The same trend was also observed for Atopobium vaginalis - there was correlation only with $\operatorname{IgG}(\beta$-positive), and Gardnerella 
vaginalis + Prevotella bivia + Porphyromonas spp. in grade II dysbiosis had no relation with the immune system at all.

Other ObA representatives - Megasphaera spp. + Veilonella spp. + Dialister spp. had no relation with the immune system, indicating that they were out of immune system control. Content of Peptostreptococ spp. was also not controlled in normocenosis and grade I dysbiosis, whereas in grade II dysbiosis, it was suppressed by $\operatorname{IgM}$ and IgG, which had negative $\beta$-coefficients.

It is interesting that Sneathia spp. + Leptotrihia spp. + Fusobacterium spp., which in normocenosis were not detected $[17,22]$, in dysbiosis had numerous relations with immune system indicators (both cellular and humoral immunity). However, the fact that their level continued to rise under such conditions, testified to the development of a secondary combined immune deficiency.

Ureaplasma urealiticum + parvum and Mycoplasma hominis + genitalium, which either were not detected or were very low in normocenosis [17, 22], in dysbiosis had an inverse dependence only on IgG (only Ureaplasma urealiticum + parvum in grade I dysbiosis). For IgA and IL10, the dependence was direct. Therefore, these pathogens also actually "slipped" out of the immune system control.

Therefore, total analysis of interrelations of the immune system indicators in blood revealed the development of systemic combined immunodeficiency and slipping of the most pathogenic microorganisms out of the control of the immune system as bacterial dysbiosis progresses.

\section{Conclusions}

1. According to the results of regression analysis, in normocenosis, NBI was determined by activation of complement $\left(\mathrm{C}_{4}\right), \mathrm{FacA}$ - as well by activation of complement $\left(\mathrm{C}_{3}\right)$ and by content of SIgA in blood; ObA and YF - by $\gamma$-INF level, and YF - also by IL8, IL10 and sIgA levels. ICPM effective value was determined by the degree of activation of Blymphocytes (number of CD22+ lymphocytes).

2. In grade I dysbiosis, NBI depended on several factors (number of $\mathrm{CD}_{22}{ }^{+}$ lymphocytes, IL6, IgM, IgG, LPI, CIC, IL10), which indicated the implementation of various mechanisms and involvement of almost all of the immune system levers to compensate for dysbiosis at the beginning of its formation. In grade I dysbiosis, ObA amount was also affected by IL6 and IL10, and MU amount - by IL1 $\beta$ and IgG.

3. In grade II dysbiosis, no factors affected NBI, which indicated that the dysbiotic processes went beyond the control of the immune system and reflected the development of 
systemic immunodeficiency. Content of IL1 $\beta$ in blood reflected a shift of the ICPM: when its level exceeded $24.6 \mathrm{pg} / \mathrm{ml}$, grade II dysbiosis was present; at IL1 $\beta$ level from $9.6 \mathrm{pg} / \mathrm{ml}$ to $24.6 \mathrm{pg} / \mathrm{ml} \mathrm{-} \mathrm{it} \mathrm{was} \mathrm{grade} \mathrm{I} \mathrm{dysbiosis,} \mathrm{and} \mathrm{at} \mathrm{IL1} \beta$ level less than $9.6 \mathrm{pg} / \mathrm{ml}$ - it was normocenosis. Factors, which anaerobic dysbiosis was the trigger for, were activation of the humoral immunity (IgG secretion) and IL10 increase.

4. General analysis of the interrelation between the immune system indicators with the number of pathogenic microbiota revealed the development of systemic combined immunodeficiency and "slipping" of the most pathogenic microorganisms out of the control of the immune system.

\section{REFERENCES}

1. Kira E.F. Bacterial vaginosis. Moscow: Medical Information Agency, 2012. 472 p. [in Russian]

2. Bautista C.T., Wurapa E., Sateren W.B., Morris S., Hollingsworth B., Sanchez J.L. Bacterial vaginosis: a synthesis of the literature on etiology, prevalence, risk factors, and relationship with chlamydia and gonorrhea infections. Mil Med Res. 2016; 3 (4). doi: 10.1186/s40779-016-0074-5.

3. Mark K.S., Tenorio B., Stennett C.A., Ghanem K.G., Brotman R.M. Bacterial vaginosis diagnosis and treatment in postmenFacAusal women: a survey of clinician practices. Menapause. 2020; 27(6): 679-683

4. Nasioudis D., Linhares I.M., Ledger W.J., Witkin S.S. Bacterial vaginosis: a critical analysis of current knowledge. BJOG. 2017; 124(1): 61-69.

5. van de Wijgert J.H.H.M., Jespers V. The global health impact of vaginal dysbiosis. Res Microbiol. 2017; 168(9-10): 859-864.

6. McKinnon L.R., Achilles S.L., Bradshaw C.S., Burgener A., Crucitti T., Fredricks D.N., Jaspan H.B., Kaul R. Kaushic C., Klatt N., Kwon D.S., Marrazzo J.M., Masson L., McClelland R.S., Ravel J., van de Wijgert J.H.H.M., Vodstrcil L.A., TachedjianG. The evolving facets of bacterial vaginosis: implications for HIV transmission. AIDS Res Hum Retroviruses. 2019; 35(3): 219-228.

7. Brusselaers N., Shrestha S., van de Wijgert J., Verstraelen H. Vaginal dysbiosis and the risk of human papillomavirus and cervical cancer: systematic review and meta-analysis. Am J Obstet Gynecol. 2019; 221(1): 9-18.

8. Reid G. Is bacterial vaginosis a disease? Appl Microbiol Biotechnol. 2018; 102(2): 553-558. 
9. Coudray M.S., Madhivanan P. Bacterial vaginosis - A brief synopsis of the literature. Eur J Obstet Gynecol Reprod Biol. 2020; 245: 143-148.

10. Muzny C.A., Taylor C.M., Swords W.E., Tamhane A., ChattFacAdhyay D., Cerca N., Schwebke J.R.. An updated conceptual model on the pathogenesis of bacterial vaginosis. J Infect Dis. 2019; 220(9): 1399-1405.

11. Ventolini G. Progresses in vaginal microflora physiology and implications for bacterial vaginosis and candidiasis. Womens Health (Lond). 2016; 12(3): 283-291.

12. Hickey R.J., Zhou X., Pierson J.D., Ravel J., Forney L.J. Understanding vaginal microbiome complexity from an ecological perspective. Transl Res. 2012; 160(4): 267-282.

13. Anderson D.J., Marathe J., Pudney J. The structure of the human vaginal stratum corneum and its role in immune defense. Am J Reprod Immunol. 2014; 71(6): 618-623.

14. Muzny C.A., Schwebke J.R. Pathogenesis of bacterial vaginosis: discussion of current hypotheses. J Infect Dis. 2016; 214(Suppl 1): 1-5.

15. Cox C., Watt A.P., McKenna J.P., Coyle P.V. Mycoplasma hominis and Gardnerella vaginalis display a significant synergistic relationship in bacterial vaginosis. Eur $\mathbf{J}$ Clin Microbiol Infect Dis. 2016; 35(3): 481-487.

16. Lipova E.V., Boldyreva M.N., Trofimov D.Yu., Vitvitskaya Yu.G. Femoflor. Urogenital infections caused by opportunistic biota in women of reproductive age (clinical and laboratory diagnostics). Manual for doctors. Moscow: DNA technology. 2015. 30 p. [in Russian]

17. Gruzevskyy OA, Vladymirova MP. [Results of a complex bacteriological study of vaginal contents under the conditions of bacterial vaginosis]. Ach biol and med. 2014;2:54-7. [in Ukrainian]

18. Gruzevskyy O.A.[Colonization resistance in vaginal dysbiosis: the state of humoral and cellular links. Bul Marine Med. 2017; 4(77):103-107. [in Russian]

19. Tits N.U. Encyclopedia of clinical laboratory tests. Moscow: Labinform. 1997. 960 p. [in Russian]

20. Delves P.J., Martin S.J., Burton D.R., Roitt I.M. Roitt's Essential Immunology, 13th Edition. 2016. Wiley-Blackwell, 576 p.

21. Gruzevskiy A.A. Colonization resistance of vaginal secretion. Journal of Education, Health and Sport. 2019; 9(2): 583-595.

22. Gruzevsky A.A., Zyablitsev S.V., Chernobrivtsev P.A. Frequency of vaginal conditional-pathogenic microflora dependency from age in conditions of normocenosis and disbiosis. Journal of Education, Health and Sport. 2017; 7(2): 509-522. 
23. Kremleva E.A., Sgibnev A.V. Proinflammatory cytokines as regulators of vaginal microbiota. Bull Exp Biol Med. 2016; 162(1): 75-78.

24. Larsen J.M. The immune response to Prevotella bacteria in chronic inflammatory disease. Immunology. 2017; 151(4): 363-374.

25. Anahtar M.N., Byrne E.H., Doherty K.E., Bowman B.A., Yamamoto H.S., Soumillon M., Padavattan N., Ismail N., Moodley A., Sabatini M.E., Ghebremichael M.S., Nusbaum C., Huttenhower C., Virgin H.W., Ndung'u T., Dong K.L., Walker B.D., Fichorova R.N., Kwon D.S. Cervicovaginal bacteria are a major modulator of host inflammatory responses in the female genital tract. Immunity. 2015; 42(5): 965-976.

26. Hilbert D.W., Smith W.L., Paulish-Miller T.E., Chadwick S.G., Toner G., Mordechai E., Adelson M.E., Sobel J.D., Gygax S.E. Utilization of molecular methods to identify prognostic markers for recurrent bacterial vaginosis. Diagn Microbiol Infect Dis. 2016; 86(2): 231-242.

27. Onderdonk A.B., Delaney M.L., Fichorova R.N. The Human Microbiome during bacterial vaginosis. Clin Microbiol Rev. 2016; 29(2): 223-238.

28. Masson L., Barnabas S., Deese J., Lennard K., Dabee S., Gamieldien H., Jaumdally S.Z., Williamson A.L., Little F., Damme L.V., Ahmed K., Crucitti T., Abdellati S., Bekker L.-G., Gray G., Dietrich J., Jaspan H., Passmore Jo-Ann S. Inflammatory cytokine biomarkers of asymptomatic sexually transmitted infections and vaginal dysbiosis: a multicentre validation study. Sex Transm Infect. 2019; 95(1): 5-12.

29. Bertran T., Brachet P., Vareille-Delarbre M., Falenta J., Dosgilbert A., Vasson M.P., Forestier C., Tridon A., Evrard B.. Slight Pro-Inflammatory Immunomodulation Properties of Dendritic Cells by Gardnerella vaginalis: The "Invisible Man" of Bacterial Vaginosis? J Immunol Res. 2016; 2016:9747480. doi: 10.1155/2016/9747480.

30. van Teijlingen N.H., Helgers L.C., Zijlstra-Willems E.M., van Hamme J.L., Ribeiro C.M.S, Strijbis K., Geijtenbeek T.B.H. Vaginal dysbiosis associated-bacteria Megasphaera elsdenii and Prevotella timonensis induce immune activation via dendritic cells. J Reprod Immunol. 2020; 138: 103085. doi: 10.1016/j.jri.2020.103085. 